\title{
HEINZ AND MCINTOSH INEQUALITIES, ALUTHGE TRANSFORMATION AND THE SPECTRAL RADIUS
}

\author{
DERMING WANG
}

Abstract. Employing Heinz and McIntosh inequalities, this paper presents a simplified proof of Yamazaki's characterization of the spectral radius: If $T_{n}$ is the $n$-th Aluthge transformation of a bounded linear operator $T$, then the sequence $\left\{\left\|T_{n}\right\|\right\}_{n=0}^{\infty}$ converges to the spectral radius of $T$.

Mathematics subject classification (2000): 47A10, 47A30.

Key words and phrases: Heinz and McIntosh inequalities, Aluthge transformation, spectral radius.

\section{REFERENCES}

[1] A. ALuthge, On p-hyponornmal operators for $0<p<1$, Integr. Equat. Oper. Th., 13 (1990), 307-315.

[2] R. BHATIA AND C. DAVIS, A Cauchy-Schwarz inequality for operators with applications, Linear Algebra Appl., 223/224 (1995), 119-129.

[3] E. HeINZ, Beiträge zur Störungstheoric der Spektralzerlegung, Math. Ann., 123 (1951), 415-438.

[4] T. Kato, A generalization of the Heinz inequality, Proc. Japan Acad. Ser. A. Math. Sci., 37 (1961), 305-308.

[5] A. McInTosh, Heinz Inequalities and Perturbation of Spectral Families, Macquarie Mathematics Reports 79-0006, Macquarie Univ., 1979.

[6] T. YAMAZAKI, An expression of the spectral radius via Aluthge transformation, Proc. Amer. Math. Soc., 130 (2002), 1131-1137. 